\title{
ARTIGO
}

d० https://doi.org/10.22481/praxis.v15i32.5059

\section{PESQUISA (AUTO)BIOGRÁFICA: NARRATIVAS DE SI COMO ESPAÇO DE FORMAÇÃO NAS ESCOLAS MULTISSERIADAS}

\author{
(AUTO)BIOGRAPHICAL RESEARCH: NARRATIVES OF SELF AS FORMATION \\ SPACE IN MULTIGRADE SCHOOLS
}

\author{
INVESTIGACIÓN (AUTO) BIOGRÁFICA: NARRATIVAS DE SI COMO ESPACIO DE \\ FORMACIÓN EN LAS ESCUELAS MULTISERARIAS
}

Charles Maycon de Almeida Mota

Universidade do Estado da Bahia - Brasil

Fabrício Oliveira da Silva

Universidade Estadual de Feira de Santana - Brasil

Jane Adriana Vasconcelos Pacheco Rios

Universidade do Estado da Bahia - Brasil

\begin{abstract}
Resumo: Este artigo analisa o processo de formação e autoformação dos docentes das escolas multisseriadas da rede pública de ensino, localizadas em Várzea do Poço - BA. Buscou-se compreender como as narrativas (auto)biográficas apresentam-se como espaço de formação de docentes ao lidarem com as diferenças na escola. Trata-se, portanto, de uma pesquisa qualitativa em que as narrativas (auto)biográficas foram centralidade da investigação. Os dispositivos da pesquisa foram a entrevista narrativa realizada, com três professores de escolas multisseriadas da Educação Básica. Esta pesquisa nos trouxe uma maior compreensão de como a entrevista narrativa se apresentou como mecanismo potente da pesquisa (auto)biográfica, que na tessitura deste trabalho, figurou como uma pesquisa-formação, por meio da qual foram desencadeadas reflexões acerca da necessidade de criação de espaços para discussão e formação com ênfase nas questões voltadas para as diferenças na escola.
\end{abstract}

Palavras-chave: Classes multisseriadas. Narrativas de si. Pesquisa (auto)biográfica.

\begin{abstract}
This article analyzes the process of formation and selftraining of the teachers of the multiseries schools of the public school system located in Várzea do Poço - BA. It was sought to understand how (auto)biographical narratives present themselves as a space for teacher training in dealing with differences in school. It is, therefore, a qualitative research in which the (auto)biographical narratives were centrality of the investigation. The research devices were the narrative interview conducted, with three teachers from multi-series schools of Basic Education. This research has brought us a greater understanding of how the narrative interview presented itself as a powerful mechanism of (auto)biographical research, which, in the context of this work, appeared as a research-formation,
\end{abstract}


through which reflections about the need to create spaces for discussion and training with an emphasis on issues of differences in school.

Keywords: (Auto)biographical research. Multi-series classes. Narratives of self.

Resumen: Este artículo analiza el proceso de formación y autoformación de los docentes de las escuelas multiserias de la red pública de enseñanza, ubicadas en Várzea del Poço - BA. Se buscó comprender cómo las narrativas (auto)biográficas se presentan como espacio de formación de docentes al lidiar con las diferencias en la escuela. Se trata, por lo tanto, de una investigación cualitativa, en que las narrativas (auto)biográficas fueron centralidad de la investigación. Los dispositivos de la investigación fueron la entrevista narrativa realizada, con tres profesores de escuelas multiserarias de la Educación Básica. Esta investigación nos trajo una mayor comprensión de cómo la entrevista narrativa se presentó como mecanismo potente de la investigación (auto) biográfica, que en la tesitura de este trabajo, figuró como una investigación-formación, por medio de la cual se desencadenaron reflexiones acerca de la necesidad de crear espacios para discusión y formación con énfasis en las cuestiones dirigidas a las diferencias en la escuela.

Palabras clave: Clases multiserarias. Investigación (auto)biográfica. Narrativas de sí.

\section{Introdução}

O trabalho emerge de uma pesquisa desenvolvida com três professores da Educação Básica, por meio da qual as narrativas de si, do percurso formativo e o trabalho em classes multisseriadas figura, como objeto de análise. Trata-se de um estudo que se originou a partir dos desdobramentos da dissertação de mestrado de um dos autores. Neste contexto, o estudo primou por dar centralidade às discussões sobre como a narratividade se instaura como processo de formação de si e de compreensão do trabalho com diferenças no campo educacional, sobretudo em se tratando do contexto de atuação de professores na Educação Básica, em que a escola é entendida como espaço de produção e de socialização de práticas que se constituem a partir das subjetividades de professores e alunos. É nesta dimensão, que as classes multisseriadas figuram como espaços na escola em que as relações evidenciam modos como professores lidam com as diferenças no desenvolvimento de suas práticas educativas.

Neste contexto, o estudo se situa na problemática do trabalho pedagógico com as diferenças em classes multisseriadas, nas quais professores têm desenvolvido práticas educativas em que as questões da diversidade se presentificam no cotidiano escolar, e transversalizam, em razão disso, o trabalho docente.. Saber lidar pedagogicamente com tais questões no contexto da multissérie tem se colocado como um desafio para muitos 
educadores, que quando se inserem num movimento de pesquisa, usam a narrativa como forma de compreender-se a si mesmo e a sua prática na escola. É a partir deste contexto situacional e formativo que o trabalho se desenvolve a partir das seguintes questões de pesquisa: Como os professores narram seus processos formativos em contextos de classes multisseriadas? Como as narrativas revelam mecanismos de formação e de autoformação que os professores desenvolvem de si e sobre si? De que maneira as concepções sobre a diferença emergem narrativamente pelas práticas educativas realizadas em classes multisseriadas?

Essas questões sinalizam possibilidade de que se depreendam modos viver e trabalhar em contextos da multisssérie, em que o trabalho pedagógico com as diferenças se coloca como elemento fundante para se pensar a história de vida e de formação desses professores a partir de suas práticas educativas e cotidianas no chão da escola. As narrativas se instauram como mecanismos de recolha de informações sobre o fazer dos professores, que se autorizam e falam por si e com propriedade sobre suas práticas, jeitos e maneiras de desenvolver o trabalho com as diferenças, tão central e necessário no contexto educacional contemporâneo.

A pesquisa (auto)biográfica tem se apresentado, nos últimos anos, como uma abordagem colaborativa para o movimento formativo de docentes. Tal abordagem vem possibilitando maneiras outras de se (re)pensar a docência diante do contexto contemporâneo no que diz respeito às relações estabelecidas pelos sujeitos que compõem os espaços escolares. Assim, fica evidente que as narrativas (auto)biográficas trazem em si uma potência formativa, no que respeita aos processos de (re)construção de sentidos e significados do fazer docente. Durante muito tempo, este fazer esteve marcado meramente pela reprodução de conteúdos, desconsiderando as diferenças existentes nas escolas e nos contextos culturais e socioeconômicos de cada comunidade.

Cabe ressaltar que esta pesquisa foi construída a partir do movimento narrativo que cada professor-colaborador se propôs a fazer, compreendendo-o como oportunidade de analisar suas reflexões sobre a própria experiência de vida e formação, tomando como referência as narrativas de si. Deste modo, buscamos aporte metodológico para este estudo na pesquisa-formação, fundamentada no método (auto)biográfico, tendo como dispositivos de pesquisa as oficinas formativas e as entrevistas narrativas.

As oficinas formativas foram inspiradas na proposta do ateliê biográfico apresentado por Delory-Momberger (2006), desdobrando-se em momentos complementares que foram desenvolvidos a partir das entrevistas narrativas necessárias para o processo de reflexividade 
formativa dos envolvidos. A pesquisa foi realizada em escolas rurais do município de Várzea do Poço, interior da Bahia, com a participação de três professores-colaboradores ${ }^{1}$.

A escolha por três docentes se deu, incialmente, pela disponibilidade destes professores em participarem das oficinas e da produção das narrativas. Além disso, consideramos que para o recorte da discussão que realizamos neste estudo, três professores seriam suficientes para que pudéssemos permitir fluidez e profundidade nas narrativas e nas trocas de experiências durante as oficinas formativas. Ademais, a entrevista narrativa se configura como um espaço privilegiado em que o professor poderá narrar, do modo que quiser, como desejar e o quanto lhe aprouver, suas experiências, gerando, às vezes, um material denso e ampliado, que permite ao pesquisador analisar muitos elementos que emergem do material, sendo por vezes, dificultoso selecionar o que é mais relevante ou não para ser tratado num texto.

Para a realização do estudo, desenvolvemos oficinas formativas com os professores colaboradores, nas quais as temáticas sobre o trabalho com as diferenças eram suscitadas para produção de reflexões. Esclarecemos que não havia no contexto da produção de oficinas uma intenção de orientar os professores para a relação de trabalhos com as diferenças nas salas multisseriadas. Muito pelo contrário, chamamos de oficinas o espaço de socialização e de demonstração narrativa que os professores faziam ao relatarem suas práticas e experiências desenvolvidas em salas multisseriadas. Como esse movimento narrativo era dialógico e de troca de experiências entre os docentes, o denominamos de oficinas formativas. Foi a partir delas que se produziram as entrevistas narrativas, pois havia o momento em que cada professor narrava suas experiências, inserindo-se num movimento de compreensão de si e de suas práticas na escola. As entrevistas foram gravadas, transcritas e devolvidas aos docentes para revisão e concordância. Após essa etapa, passamos a categorizar os elementos que emergiam das narrativas, focando o nosso olhar para compreensão de como as diferenças eram tratadas no contexto das práticas educativas dos professores em atuação nas salas multisséries.

Tomamos como objetivo da pesquisa analisar como o processo de formação e autoformação dos docentes que lecionam nas escolas multisseriadas é construído, ao lidarem com as diferenças, em seu cotidiano escolar, a partir da dinâmica de escrita e reescrita das narrativas (auto)biográficas, na relação/produção do/com o conhecimento de si. Para isto,

${ }^{1}$ Os professores-colaboradores da pesquisa possuem nomes fictícios em atendimento ao Comitê de Ética em Pesquisa, no qual a pesquisa realizada foi submetida e aprovada através do Parecer $\mathrm{n}^{\circ} 1.231 .903$ 
optamos por desenvolver um trabalho de pesquisa-formação em busca da ressignificação das trajetórias de formação.

Portanto, o presente estudo apresenta discussões relevantes sobre a pesquisa-formação por possibilitar um movimento formativo que está compreendido por Pineau (2014) em três movimentos, tomando as narrativas de si como elemento fundamental a um enveredamento para o conhecimento de si, onde a entrevista narrativa se coloca para além de um dispositivo de pesquisa, neste caso, esta foi compreendida como espaço de reflexividade formativa, ou seja, um espaço de formação.

\section{Pesquisa-formação: enveredar para o conhecimento de si}

A pesquisa-formação ressurge, a partir do movimento biográfico, com base nas discussões de Pineau (2006) entre os anos de 1983 a 1985, como uma proposta metodológica que enfatiza o compromisso do pesquisador com sua prática, focalizando uma mudança individual e coletiva, em que há uma corresponsabilidade entre o pesquisador e os colaboradores da pesquisa, no desenvolvimento da investigação, de maneira equivalente. Assim, cabe compreender que o desvelamento da pesquisa-formação está atrelado à autonomia docente, pois demanda um conhecimento de si, a partir de reflexões e compreensões feitas diante das trajetórias de formação. Josso (2010) afirma que a pesquisaformação tem sua legitimidade e a produção do saber é pautada na experiência que enfoca a coletividade, gerando todo um processo de intersubjetividade dos envolvidos.

Nota-se que o conhecimento construído na perspectiva da pesquisa-formação se dá a partir de um processo de formação simultânea, do pesquisador e dos colaboradores da pesquisa, motivado pela retroalimentação em que o formar e o formar-se acontecem, a partir das inter-relações que envolvem uma estrutura dinâmica. A pesquisa-formação está ancorada num processo de investigação-formação fundamentado na hermenêutica e na fenomenologia, por oferecer condições de análise das narrativas, que por sua vez estão sobrecarregadas das subjetividades de sujeitos que têm uma experiência de vida, uma concepção de mundo e um fazer docente repleto de sentidos e significados. Neste contexto, o sujeito toma como ponto inicial "o nexo da vida tal como se oferece ao indivíduo (e como é revivido e compreendido no conhecimento biográfico de outros indivíduos) [e que] se fundamenta no significado de determinadas vivências" (GADAMER, 1997, p. 342).

A proposta da pesquisa-formação é direcionada pela abordagem (auto)biográfica, como um pressuposto que busca concentrar esforços no processo de reflexão a respeito das 
experiências de vida, evocando pontos que são primordiais ao conhecimento de si, ocorrendo, assim, um processo de formação que toma como base o individual e o coletivo, que são transversais à vida de cada docente. Souza et al. (2012, p. 140) enfatizam que:

O sentido e a pertinência do trabalho centrado na abordagem biográfica e de seu enquadramento como uma prática de investigação-formação justifica-se porque não cabe uma teorização a posteriori sobre a prática, mas sim uma constante vinculação dialética entre as dimensões prática e teórica, as quais são expressas através da meta-reflexão do ato de narrar-se, dizer-se de si para si mesmo como uma evocação dos conhecimentos das experiências construídas pelos sujeitos.

A abordagem (auto)biográfica potencializa o processo de (auto)formação, por possibilitar que os sujeitos se coloquem como protagonistas desse processo formativo, com vistas a um pensar sobre sua própria prática, pelo qual eles poderão identificar suas fragilidades e potencialidades e reconhecer o que seria importante para o desenvolvimento de um fazer docente que venha atender às demandas contemporâneas. Considerando tais aspectos, Josso (2010, p. 122) menciona que "a reflexão sobre a prática de reflexão se realiza num duplo movimento: por um lado, pelo questionamento recíproco das subjetividades envolvidas - os referenciais individuais -, e, por outro, pelo questionamento recíproco entre o referencial de experiência e outros referenciais coletivos".

Partindo dessa vertente, podemos contemplar a pesquisa em educação, na ótica das subjetividades, como uma das inúmeras possibilidades de compreender as premissas que estão envolvidas, implícita e explicitamente, no processo educacional, em que o conhecimento de si propõe um direcionamento para a ação de formar/formando-se.

Nesse âmbito, a pesquisa-formação ancora-se na produção de sentido e significado que dão suporte à construção coletiva dos grupos, em que a experiência apresentada pelos sujeitos, nesses grupos, desencadeia a construção de um conhecimento produzido coletivamente, legitimado e validado como um pressuposto de sua formação. Considerando tais fatores, podemos mencionar que a autonomia docente vai sendo construída paralelamente a esse movimento que transversaliza a vida desses docentes, oferecendo uma gama diversificada de possibilidades para o trabalho em classes multisseriadas.

Por estar articulada ao método (auto)biográfico, a pesquisa-formação traz como objetivo o conhecer a si mesmo através de um processo de reflexão que desemboca na tomada de consciência da consciência de si, podendo mobilizar os elementos necessários à sua própria formação. Isso faz com que os docentes superem a condição de meros reprodutores de saber, aplicando-se na produção do mesmo. Dominicé (2014, p. 81) afirma que: 
[...] o estudo biográfico, apela à reflexão e resulta de uma tomada de consciência, dá origem a um material de investigação que é já o resultado de uma análise. A diversidade dos dados deve assim ser recebida como uma pluralidade de compreensão biográfica. O objetivo teórico da investigação ou a busca de uma teoria da formação tornam-se, então, indissociáveis de um aprofundamento da análise que cada um pode fazer sobre a sua formação.

Partindo dos pressupostos de uma pesquisa baseada nos percursos de vida e formação dos docentes, com enfoque sobre uma formação, em que o pesquisador se encontra com seus pares, num processo intermitente, esse pesquisador é também sujeito da pesquisa. Assim, podemos vislumbrar que a presença do professor como pesquisador requer que ele mobilize mecanismos para o conhecimento de si, buscando adentrar as questões de ordem singular como um procedimento que o prepara para a investigação-formação. Josso (2014, p. 76) nos diz que "é a presença consciente que nos permite falar de um sujeito de formação". Neste sentido, compreende-se que é na descoberta de si que o sujeito vai ganhando consciência de suas condições de sujeito aprendente, numa relação de interioridade e exterioridade, em que o outro é parte operante do processo de intersubjetividade que se estabelece em um contexto formativo.

O processo que se encontra envolvido no desenvolvimento da pesquisa-formação compreende a legitimidade do conhecimento de si, fazendo com que o docente possa definir e entender, através do decurso da própria vida, que a aprendizagem, nos procedimentos de formação sustentados pelas experiências de vida e profissão, desencadeia a teorização necessária, decorrente desse percurso formativo, fincado no trabalho com o método (auto)biográfico, pois este exige um rigor que favorece a contemplação das subjetividades através de pré-requisitos compreensivo-interpretativos, possibilitando aos sujeitos em processo uma nova perspectiva sobre o seu fazer-se docente.

Com isso, tais processos e procedimentos, que se encontram no cerne da pesquisaformação, coadunam-se ao princípio de que se faz necessária a colaboração daqueles que narram suas histórias de vida, compreendendo-se como sujeitos de mudança que intervêm nas realidades vividas, ou seja, como construtores de sua autonomia profissional, partindo da diferença e das subjetividades. Para isto, é importante apresentar quem são os professorescolaboradores que participaram da pesquisa-formação a partir do perfil biográfico como caracterização do lugar de fala dos mesmos. 


\begin{tabular}{c|c|c|c|c|c}
\multicolumn{2}{c}{ QUADRO } & $\mathbf{1}-$ Perfil biográfico - Professores de classes multisseriadas \\
Colaborador & Sexo & Idade & Residência & $\begin{array}{c}\text { Tempo de } \\
\text { docência }\end{array}$ & $\begin{array}{c}\text { Atividade além da } \\
\text { docência }\end{array}$ \\
\hline Rafaela & F & 39 anos & $\begin{array}{c}\text { Povoado Nova } \\
\text { Esperança }\end{array}$ & 24 anos & Dona de casa \\
\hline Edson & M & 49 anos & Faz. Abóbora & 29 anos & Agricultor \\
\hline Marta & F & 51 anos & Faz. Caraibinha & 36 anos & Agricultora \\
\hline
\end{tabular}

Fonte: Diário de campo do pesquisador, março de 2016

As trajetórias de vida-profissão-formação têm se colocado como perspectivas outras para a formação docente, por possibilitarem o ressurgimento de condições específicas e inerentes a cada sujeito que busca sua formação por este caminho. Neste caso, enveredar para o conhecimento de si se coloca neste trabalho como uma proposta de formação que foi sendo delineada a partir das bases e princípios da pesquisa-formação, cujo conhecimento de si foi tomado como espaço de formação na escola multusseriada, bem como categoria fundante para pensar as trajetórias de formação.

Com isso, buscamos fundamento nas concepções que destacam as narrativas (auto)biográficas como uma maneira de propor um caminho que trouxesse uma proposta de formação centrada no sujeito e nas produções de sentido que este desenvolve em suas ações, de modo que tais narrativas se tornassem a condição da reflexividade formativa, desencadeando, por isso mesmo, um processo de formação, autoformação e ecoformação.

Os enredamentos para o conhecimento de si como espaço de formação foram sendo delineados a partir do movimento das narrativas, quando cada professor-colaborador teve a oportunidade de conduzir suas reflexões acerca da própria experiência de vida e formação, tomando como ponto de referência suas narrativas e as narrativas dos outros, caracterizando a pesquisa-formação como um momento de interação pelo qual as possibilidades formativas foram se efetivando e impulsionando a construção de conhecimento.

Logo, enveredar para o conhecimento de si nos mobiliza a seguir outras direções, cujo ponto inicial se concentra na rememoração das situações vivenciadas em nossas experiências docentes, servindo como condição de uma reflexão e revisão de nosso fazer em escolas multisseriadas. Tal disposição impulsiona esses fazeres, a partir da ressignificação de nossas realidades, com vistas a garantir o respeito e o reconhecimento das diferenças, propiciando situações equânimes entre os sujeitos que frequentam nossas salas de aula.

Sendo assim, evidenciamos o conhecimento de si como categoria importante por carregar consigo esta dimensionalidade formativa, pelas diversas possibilidades de compreender as diferenças existentes em nossas escolas multisseriadas, que são apropriadas 
pelo docente que reflete a respeito de como lida com elas, (re)pensando seu lugar neste ambiente de encontro de culturas que é a sala de aula.

O conhecimento de si apresentado neste trabalho está evidenciado nas narrativas que possibilitam ao sujeito da/na formação rememorar momentos vividos no decurso de sua vida, que constituíram e constituem suas experiências, sendo estas entendidas enquanto "experiências formadoras, as quais são perspectivadas a partir daquilo que cada um viveu e vive, das simbolizações e subjetivações construídas ao longo da vida" (SOUZA, 2006, p. 95).

Entendemos que conhecer-se a si mesmo é mobilizar os elementos que possam contribuir ao processo de interioridade que o sujeito precisa desenvolver, evocando um passado que é anunciado, no presente, como perspectiva de futuro, expondo e denunciando os fatos e momentos eleitos como importantes e necessários quando são invocados.

Este procedimento docente exige uma reflexão sobre si, rememorando acontecimentos, tomando consciência daquilo que foi elemento basilar do percurso de formação/experiência na profissão docente. Neste trabalho, conhecer o outro retoma o lugar da escuta sensível e da valorização das histórias de vida dos sujeitos envolvidos nas escolas multisseriadas, como um fator fundante e formativo da docência, no qual os princípios de formação do sujeito que narra sobre si e para si esteja direcionado para a reciprocidade, criando-se maneiras de coexistência entre estes sujeitos e suas localidades. Como reitera Larrosa (2011, p. 45).

Uma cultura inclui os dispositivos para formação de seus membros como sujeitos ou, no sentido que vimos dando até aqui à palavra 'sujeito', como seres dotados de certas modalidades de experiência de si. Em qualquer caso, é como se a educação, além de construir e transmitir uma experiência 'objetiva' do mundo exterior, construísse e transmitisse também a experiência que as pessoas têm de si mesmas e dos outros como 'sujeitos'.

Coloca-se aqui a experiência de si como um fator intimamente relacionado ao processo educacional como prática social que evidencia as mobilizações que os sujeitos fazem de suas experiências e das experiências dos outros, aprendendo e apreendendo a partir da necessidade que temos de construir e transmitir experiências. Então, tais experiências deslocam-se, no sentido de valorização da vida e dos lugares em que estas são produzidas, bem como emanam dos sentidos, representações e significados constituídos nestas produções.

O conhecimento de si se coloca como uma perspectiva de outros espaços de formação na escola multisseriada, por sinalizar para as diversas veredas que poderão nos conduzir à construção de uma educação que valorize os sujeitos em suas condições de existência, compreendendo que o seu ser-fazer engloba uma multidimensionalidade responsável pelo que 
Josso (2008) considera como projeção de si, provocando uma reorientação do sujeito, que se (re)posiciona diante de suas perspectivas de futuro, estas que são, por sua vez, reavaliadas, revistas e repensadas, como parte de sua exterioridade enquanto ser-sujeito. A autora reitera que:

\begin{abstract}
A história de vida narrada é, assim, uma mediação do conhecimento de si na sua existencialidade que oferece, para a reflexão do seu autor, oportunidades de tomada de consciência dos vários registros de expressão e de representação de si, assim como sobre as dinâmicas que orientam a sua formação. (JOSSO, 2008, p. 19)
\end{abstract}

Nesta perspectiva, o conhecimento de si nos oferece condições de desenvolvimento de uma formação docente baseada em perspectivas que valorizam e consideram, como elemento importante da construção de um fazer docente condizente com o protagonismo dos que ensinam e dos que aprendem, a experiência daqueles que se encontram envolvidos no cotidiano das escolas multisseriadas. Trata-se de um espaço de formação na escola rural que é prospectado a partir do conhecimento de si e do outro, colocando-se, então, como uma condição que emerge da vontade do docente em se predispor a conhecer a si mesmo como pressuposto para o conhecimento do outro, focado em um processo de unicidade e alteridade, pelo qual se coloca, a priori, a relação do docente consigo mesmo e, a posteriori, a relação com o outro.

Nesse caso, Josso (2010) reitera que esse é um momento em que o docente toma consciência de uma consciência que deve ter sobre si mesmo, ressurgindo do coletivo, cultural e biológico, e buscando sua individuação a partir da unicidade. Isso se dá a partir de um processo que envolve revisitar pontos significantes de nossas vidas e, mais especificamente, da nossa experiência como docente.

Ao falar de sua prática pedagógica, Edson se coloca como um sujeito da experiência que vivencia o ato de ensinar/aprender a partir de reflexões que expressam concepções fundamentadas no pensamento de Paulo Freire, pois compreende que um fazer docente condizente às demandas da contemporaneidade requer um movimento de revisão, ressignificação e, às vezes, demanda até uma (re)invenção dos modos de fazer/pensar a docência em classes multisseriadas.

A sala de aula pra mim é uma troca de experiência, que tanto o professor aprende com o aluno como também o aluno aprende com o professor, e o professor tem que sempre estar buscando o novo para sua sala de aula. Sempre tem que estar trazendo aquilo que atrai a criança, que chama a atenção da criança, que o ambiente da sala de aula tem que ser um ambiente prazeroso, onde a criança vem ali pelo prazer de aprender e é isso que faz 
toda diferença no trabalho de cada um da gente. Eu já estou com 29 anos de sala de aula e eu acredito que tenho contribuído muito na formação de meus educandos. (Edson, Entrevista Narrativa, 2016)

Ao narrarem sobre si, os professores de classes multisseriadas evidenciam seus percursos na docência, revisitando momentos charneiras de suas experiências como forma de redimensionamento do fazer docente em contextos rurais. Desse modo, reiteramos que as narrativas de si possibilitam a formação docente centrada no sujeito que ensina e, ao ensinar está exposto aos processos de um apre(e)nder, onde o movimento formativo deste sujeito ensinante/aprendente perpassa por uma temporalidade relacionada a quem este docente foi - o que constituiu seu ser/fazer -, quem ele é e quem ele pretende ser.

Ao compreender-se num movimento formativo de busca constante sobre seu fazer educativo na sala de aula. Edson autoavalia-se como um sujeito que busca constantemente desenvolver práticas pedagógicas que sejam motivadoras e que despertem algum interesse em seus estudantes. Neste sentido, e como assevera Josso (2008) a existencialidade do professor tem a ver com a compreensão narrativa que o sujeito instaura de si e sobre si, ao conceber-se num papel formativo que é perene, tanto quando traz a tona a sua dimensão formativa pessoal, como elemento fundante do seu fazer pedagógico, que deve considerar, entre outros elementos, o sentido de sua prática para o outro. Nessa lógica, evidencia-se um modo narrativo de inserir-se num decurso de formação que se desenvolve em mão dupla, ou seja, tanto para si, como para os seus alunos.

O engajamento do docente nesse processo propõe-lhe uma autorreflexão, em que um dos elementos principais de sua formação se encontra na revisão de sua própria prática, despontando daí uma aprendizagem relacionada ao que se vive como docente, em sala de aula, e o que se objetiva ser, como profissional. Este redimensionamento exige processos constantes de mudança que possam agregar valores aos fazeres da docência, tendo em vista um pareamento entre os arquétipos sociais vigentes e as propostas de formação docente.

Assim, podemos dar ênfase a elementos que se encontram presentes no que se objetiva para si, a partir do vir-a-ser, desejo que surge quando o sujeito toma consciência do seu Eu, de si, redescobrindo-se como um ser no mundo, que age e interage com seus pares e compreende seu papel social, na localidade, como um mecanismo de reconfiguração de seu espaço na inter-relação com o outro.

Quando colocamos em evidência o conhecimento de si como uma premissa, em que o docente tem a oportunidade de refletir a respeito de sua experiência e formação, o fazemos a partir das contribuições e dos estudos de Josso (2010). Estes apresentam o conhecimento de si 
como um pressuposto do engajamento docente no seu próprio processo de formação, perpassando pelas questões de autonomização, individuação e interioridade, e compreendem, assim, quais são os elementos fundantes de sua prática docente, ao refletirem sobre sua intencionalidade.

As narrativas de si da professora Marta revelam um processo de entrada na profissão marcado pelo reconhecimento de seus esforços como estudante de classe multisseriada, bem como, pelo sentimento de inferiorização e invisibilidade por ser professora leiga. Isso vai sendo superado pela retomada aos estudos e pela compreensão da dimensionalidade que o ser professora tem em sua vida.

Graças ao meu esforço com 16 anos de idade fui indicada por uma das professoras que fez parte do meu processo de alfabetização como pessoa capaz de dar aulas para alunos da comunidade. Foram 20 anos como professora leiga, nome dado a quem não tinha o magistério. Confesso que daí em diante se deu uma trajetória que passei por humilhações diversas. Muitas vezes sentia uma tristeza tão grande em perceber que era "invisível" aos olhos de muitas pessoas de quem tanto queria apoio. O tempo passa e vou em busca de não desanimar, retornei aos estudos e aos poucos fui recuperando a autoestima. Hoje posso afirmar que as situações de constrangimento a que fui submetida nas diferentes situações pela qual passei no decorrer da vivência como aluna/professora, contribuiu para me manter firme acreditando que os "conflitos" existem e nos resta ter sabedoria para superá-los. Atualmente são 36 anos de serviço. Me sinto feliz, realizada por ter o privilégio de ser professora, exercer uma atividade significativa para a formação dos sujeitos, as dificuldades foram tantas, mas vem sendo superadas por acreditar que a educação é a "base" para o sucesso. (Marta, Entrevista Narrativa, 2016)

As narrativas de si desencadeiam uma maneira diferenciada de pensar sobre nossas práticas, nossas necessidades de formação e as possibilidades de intervir no mundo, pois se caracteriza como um momento de rever a nossa trajetória, como um ser no mundo, de maneira que possamos perceber como se deu o nosso caminhar. Assim, refletindo sobre o que fizeram de nós e o que fazemos com aquilo que fizeram de nós, surgem revelações que nos ajudam no processo de compreensão dos motivos que nos levaram a assumir a profissão docente, como nos vemos nesse fazer-docente e como reconhecemos o outro que está envolvido conosco nesse saber-fazer.

Nesse sentido, o movimento de narrar sobre si, conhecendo-se a si mesmo está fundado na busca que o sujeito faz de sua individuação, para entender os processos de subjetivação e sua relação com os grupos em que está inserido.Complementando tal pensamento, Souza (2006, p. 138) menciona que "o sujeito desloca-se numa análise entre o papel vivido de ator e autor de suas próprias experiências, sem que haja uma mediação 
externa de outros”. É possível, então, evidenciar na narrativa de Marta, que no decorrer de sua experiência docente mobilizou elementos que servissem como base de superação para lidar com as dificuldades enfrentadas na profissão, colaborando com o processo de formação de sua comunidade e tornando-se realizada como professora de classe multisseriada.

$\mathrm{Na}$ narrativa, a professora enfatiza o fato de ter sofrido no contexto de seu trabalho, enfatizando sua diferença em relação aos demais. A falta de formação foi o elemento balizador para que ela pudesse enfatizar os problemas que enfrentou, por ser diferente, por não ter a formação requerida e por perceber-se invisível para pessoas de quem ela esperava obter alguma ajuda. Aos dezesseis anos se torna uma professora leiga e se reconhece nessa condição como um sujeito que enfrentou desafios por atuar em escola rural, em contextos da multissérie, em que as diferenças, não só de níveis de aprendizagens de seus alunos, mas às relativas ao processo de subjetivação dos sujeitos, que os colocam em posições distintas uns das dos outros. É nessa percepção de ser diferente que Marta vê em si um problema a ser superado. Neste caso, de leiga ela precisava constituir-se enquanto professora formada, numa evidência de suas necessidades formativas para tentar sentir-se menos diferente, logo menos incapaz.

Esse sujeito passa a ser o responsável pela mobilização dos elementos próprios e intrínsecos a suas necessidades formativas, uma vez que se coloca numa condição de reflexão e autorreflexão, a partir da rememoração do seu percurso de vida, pessoal e profissional, escrevendo-se e se inscrevendo por suas narrativas, sem a intervenção de outrem, pois o conhecimento de si somente pode acontecer a partir do momento em que o próprio sujeito toma consciência da consciência de si (JOSSO, 2010), e isso só acontece no processo de individuação desse sujeito.

\section{Entrevista narrativa: dispositivo de formação nas escolas multisseriadas}

As narrativas têm se colocado como elementos de grande relevância no campo educacional por possibilitarem maneiras outras para (re)pensar a formação docente como forma de rompimento de estruturas cartesianas que durante muito tempo inspirou diversas concepções que direcionavam a formação de professores em nosso país. Conforme Jovchelovitch e Bauer (2002, p. 90) “as narrativas se tornaram um método de pesquisa muito difundido nas ciências sociais. A discussão sobre narrativas vai, contudo, muito além de seu emprego como método de investigação". Neste sentido, a narrativa pode ser tomada como 
bidimensional, ou seja, como método de investigação e como forma discursiva, trazendo vários modos de discursos.

Diante disso, é interessante enfatizar que as entrevistas narrativas se colocaram aqui como um dispositivo de formação nas escolas multisseriadas, pois contribuíram de maneira importante para o processo formativo, promovendo uma espécie de reaproximação dos professores-colaboradores com as questões abordadas no decorrer do desenvolvimento da pesquisa-formação, contribuindo significativamente no movimento de reflexividade desencadeado, por ter a oportunidade de(re)pensar a prática desenvolvida em sala de aula.

É importante reiterar que as narrativas (auto)biográficas trazem para a nossa formação como docente uma capacidade transformadora, ao mobilizar elementos do nosso ser (vivência) e do nosso fazer (experiência), fazendo com que tomemos consciência das tensões que emergem de nossa existência, compreendida como nosso ser - interioridade - e nosso fazer - exterioridade. Josso (2010, p. 204) considera que "essas tensões nascem de uma contradição entre comportamentos e ideias expressas, por um lado, pensamentos e sentimentos, por outro [...] os momentos de tensões não passam de tempos fortes de uma dialética permanente ao longo de toda existência”.

Dessa maneira acontece a humanização, a alteridade e a transcendência como metamorfoses de si, fator basilar para se compreender a dinâmica de embates e entrecruzamentos culturais que se apresentam cotidianamente na escola. Assim, "são as experiências formadoras, na força do que nos atinge, que nos sobrevêm, nos derrubam e transformam, inscritas na memória, que retornam pela narrativa não como descrição, mas como recriação, reconstrução" (BRAGANÇA, 2011, p. 159).

Neste sentido, só podemos narrar aquilo que foi vivido, experienciado e que ressurge em nossas memórias. Quando narramos, selecionamos fatos e fazemos recortes de momentos que tiveram significado em nossa existência, tenham sido, positivos ou negativos, estes momentos são eleitos de maneira a considerar um modo de ser-viver-fazer, compreendendo as ideologias, as identidades e as subjetividades, sem deixar de prospectar um vir-a-ser, um sujeito em devir. Com isso, pensamos que o professor que tem a oportunidade de construir sua narrativa (auto)biográfica, não a constrói considerando o passado como um referencial, seu referencial é o presente vivido, determinante de como os fatos serão narrados.

Ao narrar sobre seu percurso de escolarização e formação, Rafaela vai deixando evidente seu vínculo positivo com seu professor do primário (Séries Iniciais do Ensino Fundamental), deixando evidente sua satisfação quando o mesmo a convidava para ajudar nos procedimentos da rotina de sua classe, isso foi nutrindo o desejo de Rafaela pela docência. 
Sempre tive uma grande admiração, carinho e respeito pelos meus professores do primário. Eu me sentia muito orgulhosa e lisonjeada, quando o meu professor Orlando me colocava a frente ao lado dele para ajudar ele a tomar a lição dos alunos e também ajudar a resolver as quatro operações de contas no quadro. Isso só me estimulava cada vez mais, a querer estudar e me sentia a professora. Depois de 15 (quinze) anos de serviço, casada, mãe de 3 (três) filhos [...], cursei Pedagogia pelo Programa Plataforma Freire, pela Universidade do Estado da Bahia - UNEB. Fiz pós-graduação em Educação Infantil, pelo Instituto Pró-Saber. O objetivo foi adquirir novos conhecimentos para melhor contribuir para a educação como formadora de opiniões. (Rafaela, Entrevista Narrativa, 2016)

A narrativa que a professora Rafaela desenvolve revela um processo formativo que congrega os elementos que estão em sua memória e que ganham sentido ao serem retomados para demarcar o valor que se constrói sobre as experiências vividas. Neste sentido, a formação acadêmica no curso de Pedagogia é ressignificada pela lembrança de ter ajudado a um professor seu, na época do primário, fazendo evidenciar o seu perfil identitário, que a narrativa faz emergir em outro tempo, cruzando diferentes vivências com um momento experiencial do ser docente, que tem como elemento fundante a motivação que recebeu de seu professor Orlando. Isso diz muito sobre a reflexão que Rafaela faz de si, constituindo, narrativamente, modos e apreensões do processo aquisicional de conhecimentos que ela logra em seu percurso formativo, como maneira de poder desenvolver bem suas práticas educativas na escola.

Diante da narrativa que Rafaela faz de si,é possível compreender o modo como a mesma apresenta suas reminiscências, trazendo seu percurso de escolarização e formação profissional como uma forma de significação de quem ela se tornou, onde o tempo referencial para tal narrativa não foi o passado em si, mas o presente vivido. Neste pensamento, compreendemos que quem narra sua própria história de vida-formação-profissão estabelece uma dialética permanente entre o seu modo de ser-viver-fazer e sua prospecção do vir-a-ser, tendo como mote principal toda a sua experiência de vida-formação. É nesse prisma que acontece a reinvenção de si, ou seja, as ficções de si são construídas nessa dialética permanente, resultando numa metamorfose de si.

Nesse contexto das transformações que acontecem na formação dos sujeitos que produzem a escrita (auto)biográfica, a metamorfose de si acontece quando,

Ao narrarem as experiências, os sujeitos expressam representações de suas histórias de vida, narrando experiências docentes, estabelecendo significados às suas vivências numa dimensão contextual, a partir das 'experiências significativas' e das 'experiências formadoras', no processo de conhecer e de 
formação que comportam a escrita do texto narrativo. (SOUZA, 2006, p.145)

Diante de tal afirmativa, fica evidente que é no seio das representações nas narrativas de vida-profissão que os professores revelam de si para si mesmos o conhecimento que têm e se encontra interiorizado, relacionando-o às ligações que estabeleceu e/ou estabelece com o outro, no decorrer de sua história de vida. Neste movimento de interioridade/exterioridade, esses sujeitos fazem uma revisão de seu ser (vivência) e de seu fazer (experiência), revendo todos os processos que foram preponderantes para a construção e a reconstrução de suas identidades e subjetividades. Com isso, tais sujeitos se posicionam como aprendentes e ensinantes, inscrevendo-se na vida-profissão como atuantes e construtores de suas próprias histórias, em busca de sentidos e significância para sua atuação na docência.

Esse movimento de rever e conhecer a si mesmo pressupõe uma análise interpretativocompreensiva da vida-profissão, inspirada nos elementos da hermenêutica apresentada por Gadamer (1997) e presentes na obra de Grondin (2012, p. 73), coadunando com a ideia de uma fusão de horizontes. "Entender o passado não é sair do horizonte do presente, e de seus pré-juízos, para se transpor para o horizonte do passado. É na realidade, traduzir o passado na linguagem do presente, onde se fundem os horizontes do passado e do presente".

Com isso, podemos reiterar que tal momento proporcionou uma ampliação das discussões e reflexões inerentes ao conhecimento de si, evidenciando, de maneira mais contundente, as concepções dos professores de classes multisseriadas sobre as diferenças e como estes lidam com ela, em sala de aula.

Assim, ao analisar os significados de sua experiência, Rafaela constrói uma narrativa por meio da qual apresenta, um movimento de reflexividade formativa fundamentada no cuidado e respeito ao outro, revelando a importância dada ao sujeito aprendente e às dificuldades de aprendizagem que estes apresentam. Logo, consideramos que a diferença está marcada pela ausência de algumas competências e/ou habilidades especificadas num currículo oficial, direcionando práticas docentes e discursos que mais se assemelham com os elementos de uma educação fundamentada em concepções da mesmidade dos sujeitos do que a uma valorização das diferenças destes.

Por mais que já temos grandes experiências, pelo nosso tempo de profissão, o que mais nos interessa é aprendermos mais e mais. Tenho um olhar para dentro do aluno(a) é isso que eu gosto de ter. Olho para cada um, principalmente aquele com menos conhecimento, com mais dificuldades na aprendizagem, o mais quieto... alguma coisa dentro deles(as) eu vejo. Tento descobrir o que eles(as) tem de melhor para juntos alcançarmos o objetivo que querem alcançar. Reflito, com cuidado, o valor de cada um(a), afim de 
que possa chegar a absoluta compreensão da importância e contribuição de cada um na dedicação para o aprendizado. Ouço mais os alunos, não importa a idade, respeito os meus alunos para ser respeitada. E o que recebo em troca é respeito, carinho, amor e confiança. (Rafaela, Entrevista narrativa, 2016)

Aprender mais e mais significa inserir-se num processo formativo que é perene e que tem a ver com sentido para as experiências vividas. A motivação para uma formação que se constrói cotidianamente, pelo desejo de aprender sempre, move Rafaela a produzir uma atitude de singularização em seus estudantes, por meio da qual ela os vê de modo particular e busca nisso atender-lhes em suas necessidades. Isso implica reconhecer que, em classes multisseriadas, os sujeitos necessitam ser atendidos em suas demandas subjetivas, o que, necessariamente, não tem a ver com o processo de trabalhar as diferenças num movimento de homogeneização, mas de reconhecimento do outro na ação relacional dos processos de individuação, que são evidenciados nas narrativas da história de vida e de formação de cada um.

A ação docente, nesse momento, requer que o professor contemple a realidade do aluno, se colocando à disposição, numa intenção de permuta e alternância de pontos de vista, onde o professor se coloca no lugar do aluno e vice-versa, pois, somente assim, teremos a construção de uma relação recíproca entre docente e discente. Isso possibilitaria novas condições de compreensão desse sujeito que está composto por dimensões cognitivas, sociais e afetivas.

A docência em classes multisseriadas pode privilegiar situações a partir da potencialização das relações inter e intrapessoal dos sujeitos, sem abrir mão da interculturalidade, dos saberes do mundo vivido que esses sujeitos portam e do saber do mundo sistêmico. Sabe-se que não é tão simples promover essa articulação, uma vez que trazemos conosco uma sobrecarga fundada na compartimentalização dos processos, embora existam diversas possibilidades de constituir uma docência parametrizada pelo envolvimento entre professor e aluno, considerando-se as dimensões da afetividade, da cognição e de suas relações socioculturais.

\section{Considerações}

Com este trabalho, pudemos compreender que umas das potencialidades do conhecimento de si eclode no processo de retomada das memórias de nossa trajetória de vidaformação-profissão, como uma maneira de redimensionar nossas práticas docentes em outra direção que não perpetua os modelos de uma sociedade calcada na padronização. Tais práticas 
inovadoras podem se ancorar em princípios que possibilitem o desenvolvimento das capacidades criadoras dos alunos de escolas multisseriadas, elevando a potência de sua condição de ser e estar no mundo.

Neste sentido, a pesquisa-formação se apresentou como uma perspectiva instigadora de um movimento de formação simultâneo, onde pesquisador e colaboradores da pesquisa vivenciaram um processo de formar/formar-se a partir das narrativas de si evidenciadas no decorrer dessa estrutura dinâmica da pesquisa-formação em que o conhecimento de si se apresentou como espaço formativo, proporcionando reflexões sobre a própria experiência de vida e formação desses professores.

Desse modo, as entrevistas narrativas se colocaram aqui como dispositivo de formação importante nas escolas multisseriadas por trazerem sentidos outros para a formação docente na valorização e reconhecimento de significados já existentes nas localidades rurais e, também, por complementarem o movimento formativo no âmbito da pesquisa-formação, pois contribuíram de maneira significativa para uma reflexividade formativa ao (re)pensar a docência nos contextos rurais, bem como, apresentando como lidam com as diferenças na sala de aula.

A partir desse movimento formativo desencadeado no âmbito da pesquisa-formação e na entrevista narrativa ficou evidente que a formação, autoformação e ecoformação dos docentes das escolas multisseriadas vão acontecendo num fazer docente em que o contar de si para si alcança uma dimensão que valoriza as interações deste sujeito com o outro, consigo mesmo e com sua realidade de vida. Assim, a maneira como estes docentes lidam com as diferenças em seu cotidiano escolar está relacionada à sua compreensão de mundo e à forma como vivenciaram e foram tocados nos processos de formação que tiveram ao longo da vidaprofissão.

Neste caso, as diferenças são elementos de fronteiras (de)marcados pelas condições socioeconômicas dos alunos de classes multisseriadas e as dificuldades de aprendizagens e/ou deficiências que trazem.

Portanto, a pesquisa-formação e a entrevista narrativa se colocaram como espaço potente de formação de escolas multisseriadas, proporcionando reflexões sobre a necessidade de criação de espaços para discussão e formação com ênfase nas questões voltadas para as diferenças no cotidiano escolar. 


\section{REFERÊNCIAS}

BRAGANÇA, Inês Ferreira de Souza. Sobre o conceito de formação na abordagem (auto)biográfica. Educação, Porto Alegre, v. 34, n. 2, p. 157-164, mai./ago. 2011.

DELORY-MOMBERGER, Christine. Formação e socialização: os ateliês biográficos de projeto. Educação e Pesquisa, São Paulo, v. 32, n. 2, p. 359-371, mai./ago. 2006.

DOMINICÉ, Pierre. O processo de formação e alguns dos seus componentes relacionais. In: FINGER, M.; NÓVOA, A. (Orgs.). O método (auto)biográfico e a formação. 2. ed. Natal: EDUFRN, 2014. p. 77-90.

GADAMER, Hans-Georg. Verdade e método. 4. ed. Petrópolis, RJ: Vozes, 1997.

GRONDIN, Jean. Hermenêutica. 1. ed. São Paulo: Parábola Editorial, 2012.

JOSSO, Marie-Christine. Caminhar para si. Porto Alegre: EDIPUCRS, 2010.

JOSSO, Marie-Christine. As narrações centradas sobre a formação durante a vida como desvelamento das formas e sentidos múltiplos de uma existencialidade singular-plural.

Revista da FAEEBA: Educação e Contemporaneidade, Salvador, v. 17, n. 29, p. 17-30, jan./jun., 2008.

JOSSO, Marie-Christine. Da formação do sujeito... Ao sujeito da formação. In: FINGER, M.; NÓVOA, A. (Orgs.). O método (auto)biográfico e a formação. 2. ed. Natal: EDUFRN, 2014. p. 57-76.

JOVCHELOVITCH, Sandra; BAUER, Martin W. Entrevista narrativa. In.: Pesquisa qualitativa com texto, imagem e som: um manual prático. Petropólis, RJ: Vozes, 2002, p. 90/113.

LARROSA, Jorge. Tecnologias do eu e educação. In: SILVA, Tomaz Tadeu da. (Org.). O sujeito da educação: estudos foucaultianos. 8. ed. Petropólis, RJ: Vozes, 2011. p. 35-86.

PINEAU, Gaston. As histórias de vida em formação: a gênese de uma corrente de pesquisaação-formação existencial.Educação e Pesquisa, São Paulo, v. 32, n. 2, p. 329-343, mai./ago. 2006.

PINEAU, Gaston. A autoformação no decurso da vida: entre a hetero e a autoformação. In: FINGER, M. NÓVOA, A. (Org.). O método (auto)biográfico e a formação. 2. ed. Natal: EDUFRN, 2014. p. 91-110.

SOUZA, Elizeu Clementino. O conhecimento de si: estágio e narrativas de formação de professores. Rio de Janeiro: DP\&A; Salvador: EDUNEB, 2006.

SOUZA.Pesquisa narrativa e escrita (auto)biográfica: interfaces metodológicas e formativas. In: SOUZA, Elizeu Clementino; ABRAHÃO, Maria Helena Menna Barreto. (Orgs.). Tempos, narrativas e ficções: a invenção de si. Porto Alegre: EDIPUCRS; Salvador: EDUNEB, 2006. p. 135-148. 
SOUZA, Elizeu Clementino; PINTO, Ana Sueli Teixeira de; MEIRELES, Mariana Martins de.Tensões entre o local e o global:ruralidades contemporâneas e docência em escolas rurais. Revista Educação, Santa Maria, v. 37, p. 351-364, 2012.

\section{$\underline{\text { SOBRE OS AUTORES }}$}

\section{Charles Maycon de Almeida Mota}

Doutorando em Educação e Contemporaneidade, pela Universidade do Estado da Bahia (UNEB). Mestre em Educação e Diversidade pela Universidade do Estado da Bahia. É professor da Educação Básica e Psicopedagogo no Centro de Referência ao Apoio Pedagógico no município de Várzea do Poço - BA, pesquisador do DIVERSO - Grupo de Pesquisa Docência, Narrativas e Diversidade na Educação Básica. E-mail: charlesmaycon22@gmail.com

\section{Fabrício Oliveira da Silva}

Doutor em Educação e Contemporaneidade, pela Universidade do Estado da Bahia (UNEB). Mestre em Filologia e Língua Portuguesa pela Universidade de São Paulo (USP). Professor assistente da Universidade da Universidade Estadual de Feira de Santana, lotado no Departamento de Educação. Professor permanente do Programa de Pós-Graduação em Educação - PPGE/UEFS Pesquisador do Grupo de Pesquisa Narrativas, Diversidade e Docência na Educação Básica. (DIVERSO) Coordenador do Núcleo de Estudos e Pesquisas sobre Pedagogia Universitária (NEPPU). E-mail: faosilva@ uefs.br

\section{Jane Adriana Vasconcelos Pacheco Rios}

Doutora em Educação pela Universidade Federal da Bahia (UFBA). Pós- Doutora em Educação pela Universidade de São Paulo (USP). Professora Titular da Universidade do Estado da Bahia, no Departamento de Educação - Campus I. Professora Pesquisadora do Programa de Pós-Graduação em Educação e Contemporaneidade e do Programa de PósGraduação em Educação e Diversidade. Líder do Grupo de Pesquisa Docência, Narrativas e Diversidade na Educação Básica (DIVERSO). E-mail: jhanrios1@ yahoo.com.br 